\title{
Primerio registro de Corvoheteromeyenia australis (Bonetto \& Ezcurra de Drago) para o Brasil com chave taxonômica para os poriferos do Parque Estadual Delta do Jacuí, Rio Grande do Sul, Brasil
}

\author{
Maria da Conceição Marques Tavares ${ }^{1}$, Cecília Volkmer-Ribeiro ${ }^{2,3}$ \& Rosária De Rosa-Barbosa ${ }^{2}$ \\ 1 Programa de Pós-Graduação em Biociências, PUC/RS. Bolsista de Doutorado do CNPq. E-mail: mcmtavares@hotmail.com \\ ${ }^{2}$ Museu de Ciências Naturais, Fundação Zoobotânica do Rio Grande do Sul. Caixa postal 1188, 90690-000 Porto Alegre, \\ Rio Grande do Sul, Brasil. E-mail: cvolkmer@fzb.org.br; roderosa@hotmail.com \\ ${ }^{3}$ Bolsista Pesquisadora do CNPq.
}

\begin{abstract}
First report of Corvoheteromeyenia australis (Bonetto \& Ezcurra de Drago) for Brazil and taxonomic key for the sponges of Parque Estadual Delta do Jacuí, Rio Grande do Sul, Brazil. A taxonomic key is provided for the assembly of sponges of the floating meadows, in a protected deltaic area at southern Brazil. The roots of the water hyacinths Eichhornia azurea (Sw). Kunth and Eichhornia crassipes (Mart.) Solms-Laubach were seen to be the prefered substrates. The register of $C$. australis (Bonetto \& Ezcurra de Drago, 1966) is the first for Brazil enhancing a discussion of the genus.
\end{abstract}

KEY WORDS. Freshwater sponges, floating meadows, protected delta region, southern Brazil.

VolKmer Ribeiro et al. (1975), reportaram os resultados de primeiro levantamento de esponjas no Delta do Jacuí. Foram encontrados espécimes no Canal da Maria Conga e no Saco da Pólvora, ambos na ilha da Pólvora, na Ilha das Balseiras, no Canal Formoso e na Ilha das Flores, Ilha Francisco Manoel, desembocadura do rio Caí e do rio Gravataí. Foram registradas as espécies: Trochospongilla delicata Bonetto \& Ezcurra de Drago, 1967, Trochospongilla paulula (Bowerbank, 1863), Trochospongilla lanzamirandai Bonetto \& Ezcurra de Drago, 1964, Trochospongilla variabilis Bonetto \& Ezcurra de Drago, 1973, Corvospongilla seckti Bonetto \& Ezcurra de Drago, 1966, Eunapius fragilis (Leidy, 1851), Heteromeyenia stepanowii (Dybowsky, 1884) e Oncosclera navicella Carter, 1881. A maioria das esponjas ocorreu com micro-espécimes, com gêmulas, aderidos às raízes do aguapéde-baraço, Eichhornia azurea (Sw.) Kunth.

Um renovado levantamento dessa fauna realizado em 2000-2001, dentro do Programa para o Desenvolvimento Racional, Recuperação e Gerenciamento Ambiental da Bacia Hidrográfica do Guaíba (Pró-GuaíbA), no sub-programa de Proteção de Parques e Reservas Naturais, desenvolvido pela Fundação Zoobotânica do Rio Grande do Sul, teve por objetivo inicial oferecer subsídios para o monitoramento futuro da biodiversidade aquática e qualidade da água nesse ecossistema de delta interior. Tratando-se do curso inferior de uma grande bacia, o acúmulo de sedimentos que formou o delta propiciou a ocorrência de extensas áreas de camalotais, circundando todas as ilhas. Confirmaram-se esses camalotais como os sítios preferidos para ocupação pelas esponjas no Delta. O levantamento feito constitui assim, o primeiro dedicado às esponjas de camalotais na Região Neotropical. A pesquisa aportou, ainda, novos registros a nível nacional, alguns outros a nível local, confirmou outros já existentes e levou à proposta de chave taxonômica, imprescindível à execução de estudos ecológicos e monitoramentos na área do Parque que envolvam locais de ocorrência de macrófitas flutuantes.

\section{MATERIAL E MÉTODOS}

\section{Área de Estudo}

O Parque Estadual Delta do Jacuí (PEDJ) está localizado na parte centro-oriental do Estado do Rio Grande do Sul, em pleno centro geométrico da Região Metropolitana de Porto Alegre e integra uma área de 17.245 hectares (Fig. 1). É limitado pelos paralelos $29^{\circ} 56^{\prime}$ e $30^{\circ} 03^{\prime} \mathrm{S}$ e pelos meridianos $51^{\circ} 12^{\prime}$ e $51^{\circ}$ 18'W (Porto Alegre 1979), ocupando áreas dos municípios de Porto Alegre, Canoas, Eldorado do Sul, Nova Santa Rita e Triunfo. O ecossistema considerado é de delta interior, porquanto a formação de ilhas sedimentares não ocorreu diretamente no limite com o oceano, mas na cabeceira do Lago Guaíba. 


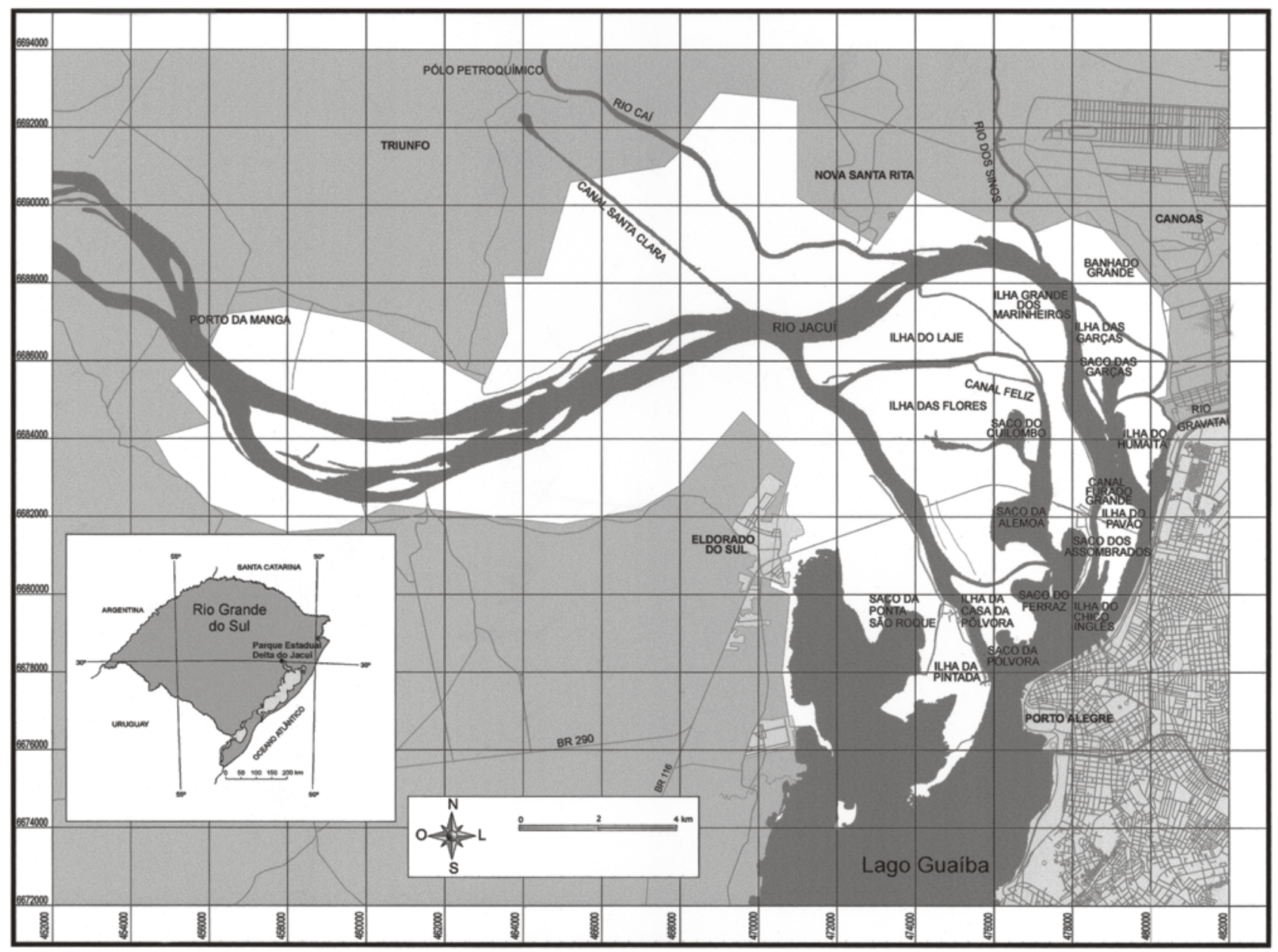

Figura 1. Mapa do Parque Estadual Delta do Jacuí, Rio Grande do Sul indicando, em fundo branco, a área do Parque e os distintos locais de proveniência dos espécimes catalogados. Elaborado pelo Laboratório de Geoprocessamento, MCN/FZB, Rio Grande do Sul.

O Parque compreende as ilhas e a planície de inundação do curso inferior do rio Jacuí, a partir da localidade de Porto da Manga em sua margem esquerda, no município de Triunfo e as terras na mesma direção em sua margem direita, no município de Eldorado do Sul; a planície de inundação do curso inferior do rio Caí até cerca de $6 \mathrm{~km}$ acima da sua desembocadura com o rio Jacuí; a região da foz do Rios dos Sinos; os canais e as 18 ilhas do Delta que somadas às demais ilhas do baixo Jacuí somam 28 ilhas. Há ainda algumas pequenas ilhas em formação, sem denominação (Oliveira \& Porto 1999).

Em termos hidrográficos, integram a drenagem principal do PEDJ o curso inferior do Rio Jacuí e dos seus afluentes na margem esquerda, rios Caí e Sinos, todos desaguando no Lago Guaíba. O rio Gravataí, apesar de não fazer parte do Parque aí aporta suas águas e sedimentos (Oliveira \& PorTo 1999). O PEDJ está inserido na mais importante Bacia Hidrográfica do Rio Grande do Sul, pois abrange a área de maior contingente populacional, a maior concentração de atividades econômicas e conseqüentemente, propicia um grande número de problemas ambientais. Estudos para avaliação da qualidade das águas do Guaíba e Delta do Jacuí, têm sido feitos desde a década de 70, pelo Departamento Municipal de Águas e Esgotos de Porto Alegre (DMAE) que passou a monitorar a qualidade desse ecossistema. Dados recentes publicados pelo DMAE mostram que as águas do Delta do Jacuí são comprometidas principalmente pela contribuição do rio Gravataí, que aporta a maior carga de esgotos, principalmente domésticos, dentre os demais contribuintes do Delta (Porto Alegre 2001).

\section{Métodos}

As coletas dos espécimes foram efetuadas em locais de amostragem que representam os ambientes aquáticos mais característicos e, entre si, mais diferenciados, desse delta, quais sejam a foz dos rios, os sacos das ilhas e os canais entre as mesmas. A metodologia de amostragem seguiu VolKMER-Ribeiro et al. (1984), incidindo sobre os camalotais e nesses, as raízes 

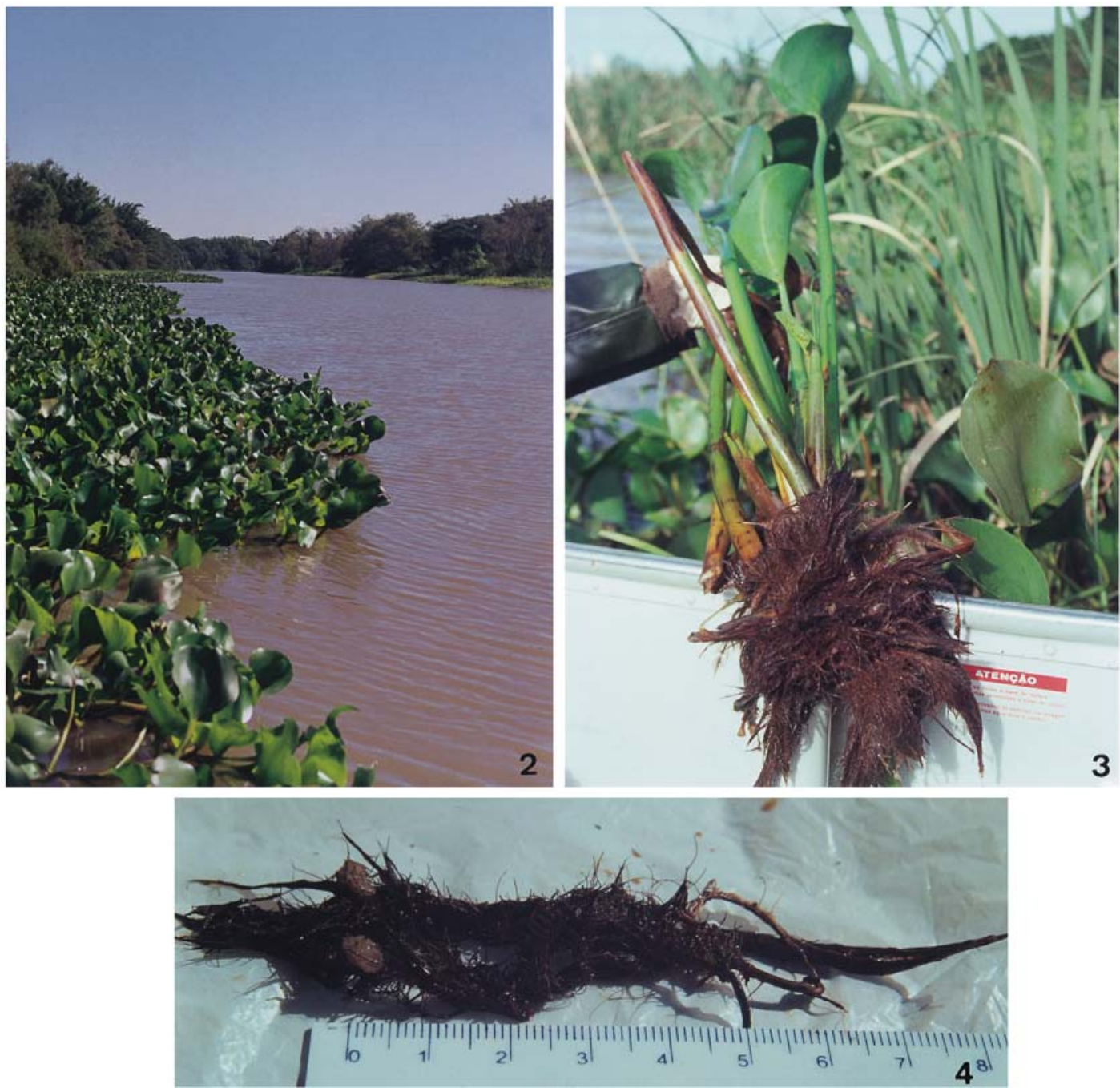

Figuras 2-4. (2) Canal Feliz no PEDJ/RS, evidenciando a vegetação de macrófitas (Eichhornia sp.) na margem direita, em cujas raízes são fixadas as esponjas; (3) exemplar de Eichhornia crassipes, evidenciando as raízes suportes para a fauna de esponja no PEDJ/RS; (4) espécimes de Radiospongilla amazonensis fixas em porções de raiz de Eichhornia sp. recentemente retirada da água, destacando a coloração bege, MCN 5926. Fotos: (2) M.C.M. Tavares, (3-4) C.S. Rodrigues.

dos aguapés Eichhornia azurea (Sw.) Kunth e Eichhornia crassipes (Mart.) Solms-Laubach (Figs 2 e 3), substratos preferenciais dessa fauna no PEDJ, particularmente os primeiros (VoLKMER-RibeIRo et al. 1975). Na verdade, o substrato dominante no parque é constituído por areia, fixada no entorno das ilhas pela orla de macrófitas (Fundação Zoobotânica do Rio Grande Do Sul 1976). Substratos duros como pedras, rochas e troncos submersos são raros nesse ambiente.

No laboratório, as partes fasciculadas das raízes foram separadas dos talos e postas a secar, primeiramente para drenagem da água sobre jornal e após dois dias, em estufa. A seguir, cada porção fasciculada de raiz foi examinada sob microscópio estereoscópico para retirada dos espécimes de esponjas, os quais foram então colocados em recipientes plásticos, catalogados e incluídos na Coleção de Porifera do Museu de Ciências Naturais (MCN-POR) da Fundação Zoobotânica do Rio Grande do Sul (FZB), conservados a seco. De cada espécime foram retiradas gêmulas com o respectivo esqueleto, submetidos à dissociação espicular em lâmina (VOLKMER-Ribeiro 1985), resultando preparações permanentes que tomaram o mesmo número de catálogo do espécime. Quando se tratava de micro-espécimes, com apenas uma gêmula, este foi todo dissociado em lâmina, pertencendo o número de registro no catálogo apenas a essa lâmina.

Assim sendo, todos os materiais coligidos com gêmulas tiveram as lâminas de dissociação estudadas para determinação 


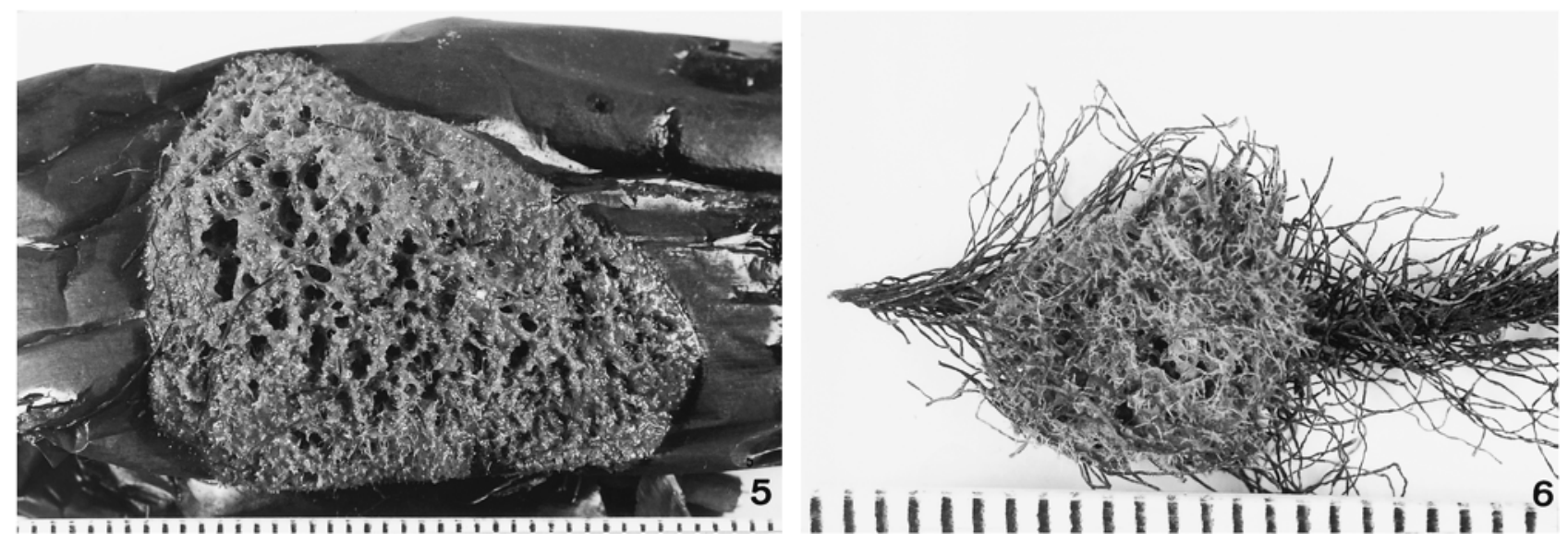

Figuras 5-6. Espécime de Radiospongilla amazonensis: (5) incrustando o caule submerso de E. crassipes, destacando o aspecto de crosta rasa. MCN 5924. Escala em milímetros $(\mathrm{mm}) ;(6)$ fixa à porção fasciculada de raiz de $E$. crassipes, destacando a forma (tendendo ao esférico) e superfície híspida, MCN 5923. Escala em milímetros (mm), fotos de G. Oliveira.

específica. Foram ainda incluídos no estudo espécimes de esponjas oriundos de amostragens feitas no PEDJ em períodos anteriores e ainda não identificados. Com o objetivo de detectar o gradiente de variação intra-específico das distintas espécies foram realizados com microscópio biológico Leitz-SMLux, equipado com câmara lúcida, desenhos dos conjuntos espiculares de representantes de todas as espécies encontradas. O conjunto espicular de C. australis foi ilustrada, também, ao microscópio óptico, visando um maior detalhamento das características das escleras. Para tanto, foi utilizado microscópio invertido modelo Olympus IX 70 com câmara digital associada ao sistema computacional Image-Pro Plus versão 4.1.0.0 (1999). As ilustrações foram úteis tanto para comparações, visando às identificações, como para a elaboração da chave. Alguns espécimes foram fotografados in vivo ou em estúdio, já conservados.

Foram realizadas 50 mensurações micrométricas de cada categoria de espícula dos conjuntos espiculares das espécies registradas.

A distribuição considerada para cada espécie refere-se aos registros até aqui operados para o Estado do Rio Grande do Sul.

\section{RESULTADOS}

\section{Spongillidae Gray, 1867}

\section{Eunapius Gray, 1867 Eunapius fragilis (Leidy, 1851)}

Fig. 7

Spongilla fragilis Leidy, 1851: 278.

Eunapius fragilis; Penney \& Racek, 1968: 25 (e sinonímia); Volkmer-Ribeiro et al., 1975: 39; De Rosa-Barbosa, 1984: 129.

Material examinado: Brasil, Rio Grande do Sul: Porto Alegre, (Parque Estadual Delta do Jacuí, Canal Feliz), 09.V.2000,
MCN-POR 5543, 5563, 5565, 5569-70, M.C.M. Tavares, R. De R. Barbosa \& G. Cunha leg.

Dimensões das escleras: megascleras óxeas com comprimento 170-290 $\mu \mathrm{m}$ e média $237 \mu \mathrm{m}$, largura 7,5-17,5 $\mu \mathrm{m}$ e média 11,95 $\mu \mathrm{m}$; gemoscleras óxeas, raramente estrôngilos com comprimento 90-175 $\mu \mathrm{m}$ e média 130,2 $\mu \mathrm{m}$; largura 5-12,5 $\mu \mathrm{m}$ e média $9,0 \mu \mathrm{m}$.

Os espécimes aqui registrados incrustavam raízes de $E$. azurea. No Rio Grande do Sul a espécie foi registrada em lago artificial no Parque Santa Rita, Farroupilha, na Lagoa dos Quadros, Osório; no rio Jacuí, General Câmara (De Rosa-Barbosa 1984). Mais recentemente foi encontrada pelas autoras no Passo da Ilha, rio Tainhas, Bacia do Taquari-Antas, São Francisco de Paula. Trata-se de uma espécie que tem preferência por incrustar substratos rochosos, como acontece no rio Tainhas, sendo rara em substratos vegetais.

\section{Radiospongilla Penney \& Racek, 1968 R. amazonensis Volkmer-Ribeiro \& Maciel, 1983} Fig. 8

Radiospongilla amazonensis; Volkmer-Ribeiro \& Maciel, 1983: 255

Radiospongilla crateriformis; Volkmer-Ribeiro et al., 1981: 16 (figs 23-29) non Radiospongilla crateriformis (Potts, 1882); De RosaBarbosa, 1984: 129.

Material examinado: BrasiL, Rio Grande do Sul: Porto Alegre (Parque Estadual Delta do Jacuí, Saco do Quilombo), 09.V.2000, MCN-POR 4618, 4651 e 4735, R. De R. Barbosa \& G. Cunha leg.; Saco do Ferraz, 26.VI.2002, MCN-POR 5923, 5924, M.C.M. Tavares, R. De R. Barbosa e G. Cunha leg.; Eldorado do Sul, Saco da Ponta do São Roque, 18.I.2000, I. Heiderich leg., MCNPOR 4686.

Dimensões das escleras: megascleras estrôngilos com comprimento 190-280 $\mu \mathrm{m}$ e média 235,2 $\mu \mathrm{m}$; largura 5-15 $\mu \mathrm{m}$ 


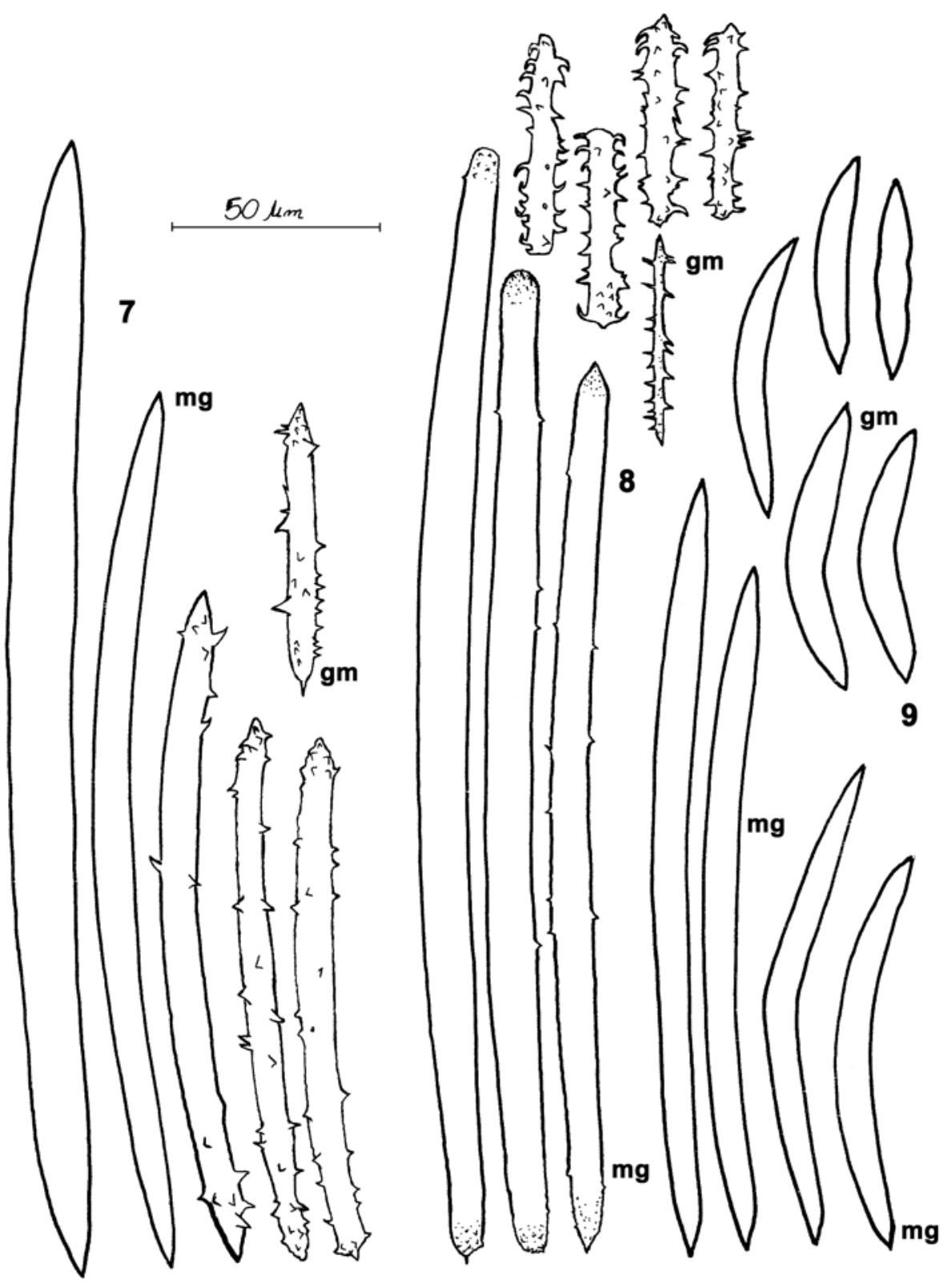

Figuras 7-9. Desenhos à câmara lúcida dos conjuntos espiculares: (7) Eunapius fragilis, megascleras óxeas (mg), gemoscleras óxeas e estrôngilos (gm); (8) Radiospongilla amazonensis, megascleras estrôngilos (mg), gemoscleras óxeas e estrôngilos (gm); (9) Oncosclera navicella, megascleras óxeas (mg), gemoscleras óxeas (gm). Escala $50 \mu \mathrm{m}$.

e média $11,4 \mu \mathrm{m}$; gemosclera óxea e estrôngilo com comprimento 42,5-60 $\mu \mathrm{m}$ e média 52,1 $\mu \mathrm{m}$; largura: 3,7-7,5 $\mu \mathrm{m}$ e média $5,3 \mu \mathrm{m}$.

Os espécimes MCN 5923 e 5924, que não possuíam gêmulas, foram determinados através da comparação de suas megascleras com os espécimes gemulíferos. Os exemplares aqui registrados incrustavam partes submersas (raiz e caule) de $E$. crassipes. Para o Estado a espécie havia sido registrada como $R$. crateriformis para a Lagoa Negra, Parque Estadual de Itapuã, Viamão, (Volkmer-Ribeiro et al. 1981) em banhado à margem da rodovia BR 386, Montenegro, e em açude na Fazenda Delapieve, Triunfo (De Rosa-Barbosa 1984).

Revista Brasileira de Zoologia 20 (2): 169-182, junho 2003 


\section{Heteromeyenia Potts, 1881 Heteromeyenia stepanowii (Dybowsky, 1884)} Fig. 15

Dosilia stepanowii [sic] Dybowsky, 1884: 507

Heteromeyenia stepanowii; Volkmer-Ribeiro et al., 1975: 40-41; Volkmer-Ribeiro \& Grosser, 1981: 177-79; Volkmer-Ribeiro et al., 1981: 21; De Rosa-Barbosa, 1984: 132.

Material examinado: Brasil, Rio Grande do Sul: Nova Santa Rita (Parque Estadual Delta do Jacuí, Rio Caí), 10.V.2000, MCNPOR 5485-87, 5489, 5491-94, 5497-5500, 5518-20, 5524-25; 22.VIII.2001, MCN-POR 5586-90; Porto Alegre (Saco do Quilombo), 09.V.2000, MCN-POR 5518-20, 5524-25, 5531-32, 5535, 5537; Canal Feliz, 09.V.2000, MCN-POR 5551, 5554, 5559, $5566,5571,5574,5580,5582 ;$ 22.VIII.2001, MCN 5591-92; Saco da Alemoa, 09.V.2000, MCN 5504-5507, 5509-11; 23.VIII.2001, MCN-POR 5593-94, 5596, 5598-5600, 5602-03, 5607, 5608-16, 5622-23, 5625-26; Saco do Ferraz, 23.VIII.2001, MCN-POR 5629$32,5637,5642,5645,5649,5658,5664,5666-67,5670,5680$, 5683, 5687-88, 5691, 5393-94, 5696, 5698-5701, 5703-04, 5708, 5711-12, 5714, 5716, 5718, 5720-21, 5723, 5726, 5734, 5738, 5742; Saco dos Assombrados, 23.VIII.2001, MCN-POR 575759, 5761-62, 5778, 5793, 5795, 5797; Canal Furado Grande, 23.VIII.2001, MCN-POR 5807-09. M.C.M. Tavares, R. De R. Barbosa \& G. Cunha leg.

Dimensões das escleras: megascleras óxeas com comprimento de 200-310 $\mu \mathrm{m}$ e média $254,4 \mu \mathrm{m}$; largura 7,5$12,5 \mu \mathrm{m}$ e média $10,3 \mu \mathrm{m}$. Microscleras óxeas com comprimento $57,5-87,5 \mu \mathrm{m}$ e média $76,6 \mu \mathrm{m}$; largura $2,5-5,0 \mu \mathrm{m}$ e média 3,5 $\mu \mathrm{m}$. Gemoscleras anfidiscos com comprimento 45-72,2 $\mu \mathrm{m}$ e média $57,5 \mu \mathrm{m}$; largura 3,7-7,5 $\mu \mathrm{m}$ e média $5,5 \mu \mathrm{m}$.

Heteromeyenia stepanowii é a segunda espécie em abundância no PEDJ depois de Trochospongilla paulula. Dos 121 espécimes listados, 78 foram encontrados incrustando raiz de $E$. azurea e 43 de E. crassipes. No Rio Grande do Sul a espécie foi registrada para o arroio do Fão, rio Jacuí em Soledade; barragem Saturnino de Brito, rio Ibicuí-Mirim em Santa Maria; açude da Fazenda das Marrecas em Montenegro; lagoa da confluência dos rios Ibicuí-Mirim com Toropí, em São Vicente do Sul; açude da Fazenda Delapieve, arroio Passo Raso do rio Jacuí em Triunfo; Rio Caí em Canoas; rio Gravataí entre Canoas e Porto Alegre.

\section{Trochospongilla Vejdovsky, 1883 Trochospongilla paulula (Bowerbank, 1863) Fig. 10}

Spongilla paulula Bowerbank, 1863: 454.

Trochospongilla paulula; Volkmer-Ribeiro \& De Rosa-Barbosa, 1972: 310 (redescrição).

Trochospongilla delicata; Volkmer-Ribeiro et al., 1975: 37 (fig. 1b) non Trochospongilla delicata Bonetto \& Ezcurra de Drago, 1967 sensu Volkmer-Ribeiro \& De Rosa-Barbosa, 1972: 330; De Rosa-Barbosa, 1984: 130.

Material examinado: BrasiL, Rio Grande do Sul: Nova Santa Rita (Parque Estadual Delta do Jacuí, Rio Caí), 10.V.2000, MCNPOR 5488, 5490, 5495, 5501; 22.VIII.2001, MCN-POR 5585; Porto Alegre (Saco da Alemoa), 10.V.2000, MCN-POR 5508; 23.VIII.2001, MCN-POR 5595, 5597, 5601, 5604, 5606, 561719, 5621, 5624; Saco do Quilombo, 09.V.2000, MCN-POR 551214, 5517, 5521-23, 5526, 5530, 5533-34, 5536; Canal Feliz,
09.V.2000, MCN-POR 5538-41, 5549-50, 5553, 5556-58, 5562, 5564, 5572-73, 5575-76, 5579, 5581; Saco do Ferraz, 23.VIII.2001, MCN-POR 5627-28, 5633-36, 5639-41, 5643-44, 5646-48, 5650-57, 5659-60, 5663, 5665, 5668-69, 5671-74, 5676$79,5681-82,5684,5689-90,5692,5695,5697,5702,5705-07$, 5709-10, 5713, 5715, 5717, 5722, 5724-25, 5727-33, 5735, 5737, 5740-41, 5743-44, 5746-51, 5753-55; Saco dos Assombrados, 23.VIII.2001, MCN-POR 5756, 5760, 5763, 5765, 5767-68, 577071, 5774, 5776-77, 5779, 5785-86, 5788, 5790-92, 5794, 5796, 5799, 5801. M.C.M. Tavares, R. De R. Barbosa \& G. Cunha leg.

Dimensões das escleras: megascleras óxeas com comprimento 210-320 $\mu$ m e média 271,1 $\mu \mathrm{m}$; largura 10-20 $\mu \mathrm{m}$ e média $13,2 \mu \mathrm{m}$. Gemoscleras anfidiscos com comprimento 15-23,7 $\mu \mathrm{m}$ e média $20,1 \mu \mathrm{m}$; largura 3,7-7,5 $\mu \mathrm{m}$ e média $5,6 \mu \mathrm{m}$.

O registro de Trochospongilla delicata para o PEDJ (VOLKMERRibeiro et al. 1975) foi operado sobre espécimes agora identificados como T. paulula (MCN-POR 273, 275). A correção dessa identificação deve-se aos inúmeros exemplares coletados no projeto em curso os quais permitiram estudos comparados dos desenhos em câmera lúcida das gemoscleras, verificadas como sujeitas a uma gama muito grande de variações que incidem principalmente sobre as dimensões do eixo. O fato levou à constatação da ausência de $T$. delicata no Parque Estadual Delta do Jacuí, já que aquele registro era o único existente não havendo sido confirmado na presente amostragem. T. delicata apresenta-se agora com apenas um registro para o Estado, no rio Jacuí, General Câmara (DE Rosa-BARbosa 1984).

Dos 146 espécimes registrados, 100 foram encontrados em raízes de E. azurea e 46, em raízes E. crassipes. T. paulula tem registro no Estado para os rios Jacuí em General Câmara, Caí em Nova Petrópolis; em lagoa na confluência dos rios IbicuíMirim com Toropí, São Vicente do Sul, e em Açude na fazenda Delapieve, Triunfo (DE Rosa-Barbosa 1984).

\section{Trochospongilla minuta (Potts, 1887) Fig. 12}

Meyenia minuta; Potts, 1887: 228

Trochospongilla minuta; Volkmer-Ribeiro \& De Rosa-Barbosa, 1972: 314; Volkmer-Ribeiro, 1973: 137 (redescrição); De Rosa-Barbosa, 1984: 131; Volkmer-Ribeiro \& De Rosa-Barbosa, 1985: 90.

Material examinado: BrasiL, Rio Grande do Sul: Porto Alegre (Parque Estadual Delta do Jacuí, Saco da Alemoa), 23.VIII.2001, MCN-POR 5620; Saco do Ferraz, 23.VIII.2001, MCN-POR 5661$62,5675,5685-86,5719,5736,5739,5745,5752$; Saco dos Assombrados, 23.VIII.2001, MCN-POR 5764, 5766, 5769, 577273, 5775, 5780-84, 5787, 5789, 5798, 5800, 5802-05. M.C.M. Tavares, R. De R. Barbosa \& G. Cunha leg.

Dimensões das escleras: megascleras óxeas com comprimento $87,5-245 \mu \mathrm{m}$ e média $161,3 \mu \mathrm{m}$; largura 5,0 a 12,5 $\mu \mathrm{m}$ e média 7,9 $\mu \mathrm{m}$. Gemoscleras anfidiscos com comprimento 8,7$20 \mu \mathrm{m}$ e média $11,2 \mu \mathrm{m}$; largura $3,7-7,5 \mu \mathrm{m}$ e média $5,7 \mu \mathrm{m}$.

A espécie tem aqui seu primeiro registro para o PEDJ. Dos 30 espécimes registrados, oito incrustavam raízes de $E$. azurea e 22 de $E$. crassipes. No Rio Grande do Sul tem ocorrências registradas para o rio Caí, em Nova Petrópolis e em Montenegro; para o Arroio Touro Passo, contribuinte do rio Uruguai, em Uruguaiana; para a lagoa na confluência dos rios Ibicuí-Mirim com o Toropí, em São Vicente do Sul; para o rio Jacuí, em General Câmara e em São Jerônimo/Butiá (De Rosa-Barbosa 1984). 


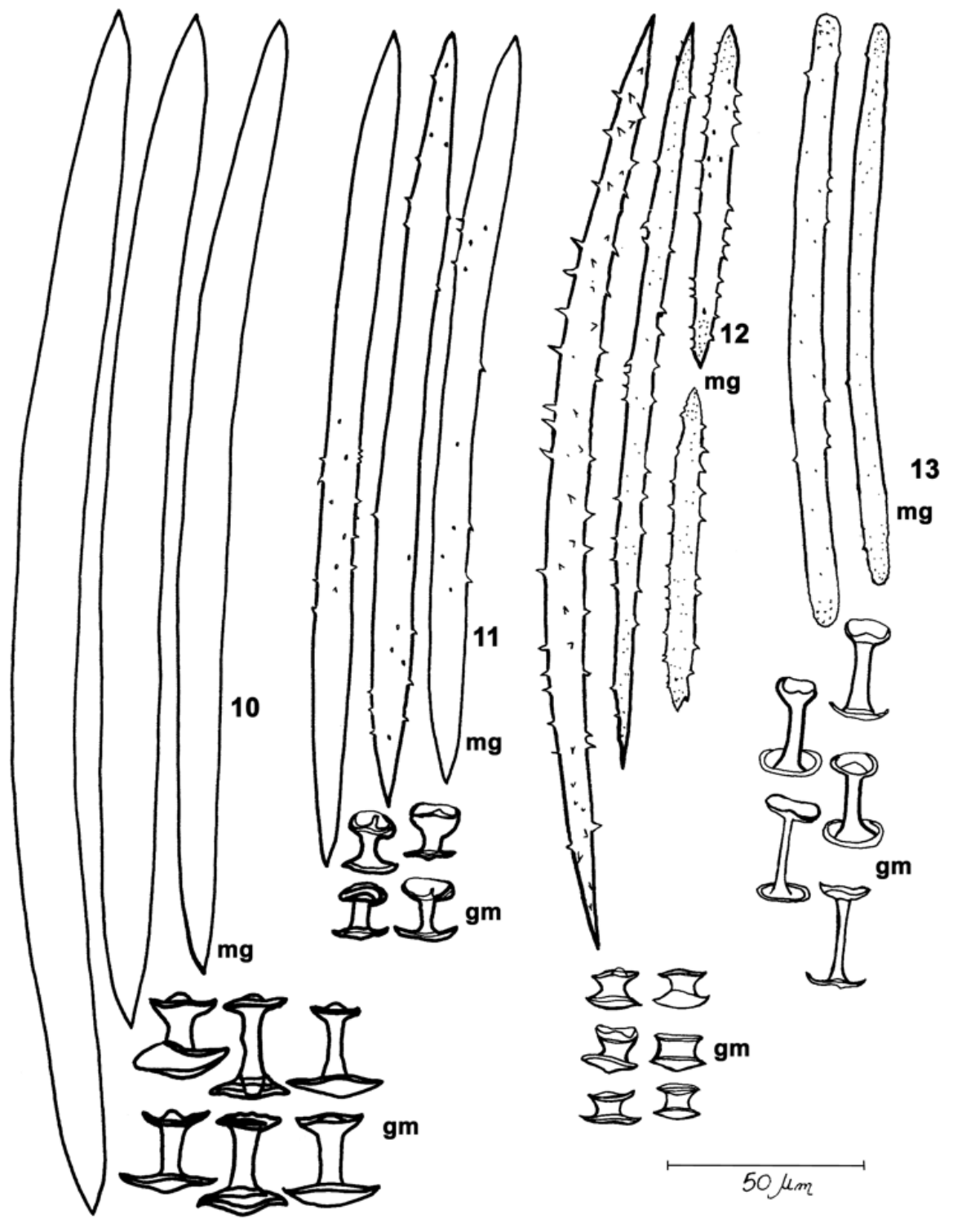

Figuras 10-13. Desenhos à câmara lúcida dos conjuntos espiculares: (10) Trochospongilla paulula, megascleras óxeas (mg), gemoscleras anfidiscos (gm); (11) Trochospongilla variabilis, megascleras óxeas (mg), gemoscleras anfidiscos (gm); (12) Trochospongilla minuta, megascleras óxeas (mg), gemoscleras anfidiscos (gm); (13) Trochospongilla lanzamirandai, megascleras estrôngilos (mg), gemoscleras anfidiscos (gm). Escala $50 \mu \mathrm{m}$.

\section{T. Ianzamirandai Bonetto \& Ezcurra de Drago, 1964}

Fig. 13

Trochospongilla lanzamirandai Bonetto \& Ezcurra de Drago, 1964: 333; Volkmer-Ribeiro \& De Rosa-Barbosa, 1972: 311 (redescrição); Volkmer-Ribeiro et al., 1975: 36; De Rosa-Barbosa, 1984: 131.

Material examinado: BrasiL, Rio Grande do Sul: Nova Santa Rita (Parque Estadual Delta do Jacuí, Rio Caí), 10.V.2000, MCN-
POR 5496; Porto Alegre, Saco da Alemoa, 10.V.2000, MCN-POR 5502, Saco do Quilombo, 09.V.2000, MCN-POR 5516, 552729; Canal Feliz, 09.V.2000, MCN-POR 5544, 5555, 5560, 5568, 5578; Saco dos Assombrados, 23.VIII.2001, MCN-POR 5806. M.C.M. Tavares, R. De R. Barbosa \& G. Cunha leg.

Dimensões das escleras: megascleras estrôngilos com comprimento 112,5-157,5 $\mu \mathrm{m}$ e média 139,9 $\mu \mathrm{m}$; largura 5-7,5 $\mu \mathrm{m}$ e média 5,9 $\mu \mathrm{m}$. Gemoscleras anfidiscos com comprimento 20$25 \mu \mathrm{m}$ e média $22,2 \mu \mathrm{m}$; largura $2-3,7 \mu \mathrm{m}$ e média $2,4 \mu \mathrm{m}$.

Revista Brasileira de Zoologia 20 (2): 169-182, junho 2003 

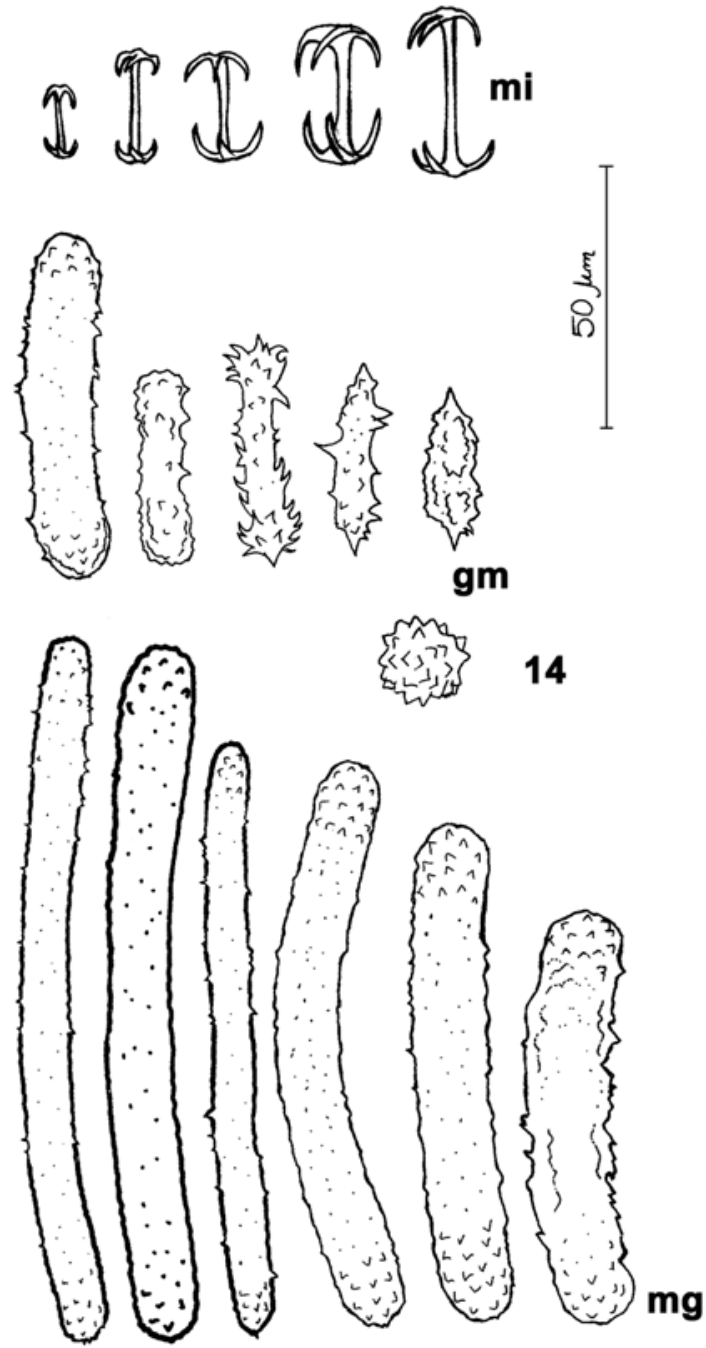

Figuras 14-15. Desenhos à câmara lúcida dos conjuntos espiculares: (14) Corvospongilla seckti megascleras estrôngilos (mg), gemoscleras óxeas e estrôngilos (gm), microscleras isoquelas (mi); (15) Heteromeyenia stepanowii, megasclera óxeas (mg), gemosclera anfidiscos (gm), microscleras óxeas (mi). Escala $50 \mu \mathrm{m}$

Os 12 espécimes registrados incrustavam raízes de Eichhornia, sendo nove de E. azurea e três de E. crassipes. No Rio Grande do Sul a espécie foi registrada para o arroio do Fão, rio Jacuí, Soledade; rio Caí (curso superior), em Nova Petrópolis; lagoa na confluência dos rios Ibicuí-Mirim com Toropí, em São Vicente do Sul; rio Jacuí, em General Câmara; rio Caí (curso inferior), em Triunfo/Canoas; Rio Gravataí, em Porto Alegre (De Rosa-Barbosa 1984).

\section{T. variabilis Bonetto \& Ezcurra de Drago, 1973} Fig. 11

Trochospongilla variabilis Bonetto \& Ezcurra de Drago, 1973: 15;

Volkmer-Ribeiro et al., 1975: 37; De Rosa-Barbosa, 1984: 132;

Volkmer-Ribeiro \& De Rosa-Barbosa, 1985: 90.

Material examinado: BrasiL, Rio Grande do Sul: Nova Santa Rita (Parque Estadual Delta do Jacuí, Rio Caí), 21.VIII.74, MCNPOR 277, S.M. Pauls leg.

Revista Brasileira de Zoologia 20 (2): 169-182, junho 2003 
Dimensões das escleras: megascleras óxeas com comprimento $130-237,5 \mu \mathrm{m}$ e média $209,9 \mu \mathrm{m}$; largura $5-12,5 \mu \mathrm{m}$ e média $9,5 \mu \mathrm{m}$. Gemoscleras anfidiscos com comprimento 15 $20 \mu \mathrm{m}$ e média $17,3 \mu \mathrm{m}$; largura 2,5-5 $\mu \mathrm{m}$ e média $3,8 \mu \mathrm{m}$.

O material de T. variabilis examinado incrustava raiz de E. azurea e corresponde ao único registro, até o presente feito, para o PEDJ (VolKMER-Ribeiro et al. 1975). A espécie tem ocorrência registrada no Rio Grande do Sul, para o rio Caí, Triunfo/ Canoas e para açude no Morro Santana, Porto Alegre (De RosaBarbosa 1984)

\section{Corvospongilla Annandale, 1911 C. seckti Bonetto \& Ezcurra de Drago, 1966} Fig. 14

Corvospongilla seckti Bonetto \& Ezcurra de Drago, 1966: 133, 1967: 332, 337; 1969: 352; 1970: 52, 55.

Corvospongilla böhmii Volkmer-Ribeiro et al., 1975: 38 (fig. 7) non Corvospongilla böhmii (Hilgendorf, 1883); Volkmer-Ribeiro \& Grosser, 1981: 177; Volkmer-Ribeiro et al., 1981: 16 (figs 6-9); De Rosa-Barbosa, 1984: 130 (sinônimo novo)

Material examinado: Brasil, Rio Grande do Sul: Eldorado do Sul (Parque Estadual Delta do Jacuí, Rio Jacuí, margem esquerda), 14.VI.74, MCN-POR 278; Porto Alegre, Canal da Maria Conga, 5.IV.74, MCN-POR 280. S.M. Pauls leg.

Dimensões das escleras: megascleras estrôngilos do esqueleto com comprimento 100-162,5 $\mu \mathrm{m}$ e média 142,4 $\mu \mathrm{m}$; largura 5-15 $\mu \mathrm{m}$ e média $8,5 \mu \mathrm{m}$; megascleras estrôngilos curtos da cápsula com comprimento 52,5-100 $\mu \mathrm{m}$ e média $81,0 \mu \mathrm{m}$; largura 10-17,5 $\mu \mathrm{m}$ e média 13,8 $\mu \mathrm{m}$. Microscleras isoquelas com comprimento $15-30 \mu \mathrm{m}$ e média $21,4 \mu \mathrm{m}$; largura 1,25-3,7 $\mu \mathrm{m}$ e média $2,2 \mu \mathrm{m}$. Gemoscleras óxeas e estrôngilos com comprimento: $17,5-55,0 \mu \mathrm{m}$ e média $34,9 \mu \mathrm{m}$; largura $7,5-17,5 \mu \mathrm{m}$ e média $10,5 \mu \mathrm{m}$.

O material examinado foi o mesmo registrado por VolKMER-Ribeiro et al. (1975), como C. bohmi, já que não se logrou amostragem de exemplares dessa espécie no atual levantamento. A raridade da ocorrência de $C$. seckti no PEDJ deve ser atribuída a que a espécie tem por habitat preferido o bentos rochoso de rios (BATISTA \& VolKMER-Ribeiro 2002) sendo sua ocorrência em substratos vegetais rara. DE Rosa-BARBOSA (1988) entendeu que o material de Corvospongilla ocorrente no PEDJ deveria ser identificado como C. seckti e não C. bohmi sem efetuar no entanto o registro da nova sinonímia, agora feito. No PEDJ, a espécie foi encontrada incrustando raízes de $E$. azurea.

A espécie foi registrada para o Rio Grande do Sul, para o rio Jacuí, à jusante da Barragem Itaúba, em Arroio do Tigre; Barragem Saturnino de Brito, Rio Ibicuí/Mirim, em Santa Maria; rio Jacuí, em General Câmara; Rio Jacuí, em São Jerônimo (DE Rosa-BARBosa 1984).

\section{Corvoheteromeyenia Ezcurra de Drago, 1979 C. australis (Bonetto \& Ezcurra de Drago, 1966) Figs 16-24}

Corvomeyenia australis Bonetto \& Ezcurra de Drago, 1966: 137. Corvoheteromeyenia australis; Ezcurra de Drago, 1979: 110 (redescrição).

Material examinado: BrasiL, Rio Grande do Sul: Porto Alegre
(Parque Estadual Delta do Jacuí, Canal Feliz), 09.V.2000, MCNPOR 5545-47, M.C.M. Tavares, R. De R. Barbosa \& G. Cunha leg.

Dimensões das escleras: megasclera óxeas com comprimento de 47,5-87,5 $\mu \mathrm{m}$ e média $68,8 \mu \mathrm{m}$; largura 2,5-5,0 $\mu \mathrm{m}$ e média 3,5 $\mu \mathrm{m}$. Microsclera isoquela com comprimento $15-25 \mu \mathrm{m}$ e média 19,6 $\mu \mathrm{m}$; largura 1,2-2,5 $\mu \mathrm{m}$ e média 1,9 $\mu \mathrm{m}$. Microsclera birrotulada com rótulas diminutas com comprimento 20 $55 \mu \mathrm{m}$ e média $40,2 \mu \mathrm{m}$; largura $2,3-3,7 \mu \mathrm{m}$ e média $3,2 \mu \mathrm{m}$. Gemosclera anfidisco curto com comprimento 47,5-77,5 $\mu \mathrm{m}$ e média 54,3 $\mu \mathrm{m}$; largura 3,7-5,0 $\mu \mathrm{m}$ e média 4,9 $\mu \mathrm{m}$. Gemosclera anfidisco longo com comprimento $62,5-90 \mu \mathrm{m}$ e média $73 \mu \mathrm{m}$; largura 3,7-6,2 $\mu \mathrm{m}$ e média $5,0 \mu \mathrm{m}$.

A espécie tinha ocorrência até o presente registrada para a Argentina na localidade tipo, Laguna Setúbal ou Guadalupe, além do banhado Don Felipe e laguna Carabajal, todos locais situados na província de Santa Fé (Ezcurra de Drago 1979) e com características muito semelhantes às de ocorrência das esponjas no PEDJ.

Os materiais agora estudados constituíam três micro-espécimes, incrustando raízes de E. azurea, com poucas gêmulas, que tiveram de ser totalmente dissociados para fins de identificação possibilitando todavia a catalogação das lâminas permanentes resultantes e as fotos em microscopia óptica. A identificação foi fundamentada nas características das gemoscleras, que se apresentam em duas categorias distintas em forma e tamanho. As gemoscleras longas apresentam as rótulas geralmente umbonadas com seus espinhos em forma de gancho voltados em direção ao eixo. As curtas apresentam as rótulas mais planas e expandidas com seus espinhos menores e menos curvos.

\section{Potamolepidae Brien, 1967 \\ Oncosclera Volkmer-Ribeiro, 1970 Oncosclera navicella (Carter, 1881)}

Fig. 9

Spongilla navicella, Carter, 1881: 87, est. 5, fig. 4a-g.

Oncosclera navicella Volkmer-Ribeiro, 1970: 437 (redescrição);

Volkmer-Ribeiro et al., 1975; De Rosa-Barbosa, 1984: 133;

Tavares \& Volkmer-Ribeiro, 1997: 103 (redescrição).

Material examinado: BrasiL, Rio Grande do Sul: Porto Alegre (Parque Estadual Delta do Jacuí, Saco da Alemoa), 10.V.2000, MCN-POR 5503; Saco do Quilombo, 09.V.2000, MCN-POR 5515; Canal Feliz, 09.V.2000, MCN-POR 5542, 5548, 5552, 5561, 5567, 5577. M.C.M. Tavares, R. De R. Barbosa \& G. Cunha leg. Dimensões das escleras: megascleras óxeas com compri-

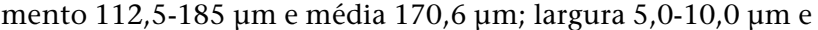
média 7,4 $\mu \mathrm{m}$. Gemoscleras óxeas com comprimento 27,5-127,5 $\mu \mathrm{m}$ e média 71,7 $\mu \mathrm{m}$; largura 7,5-12,5 $\mu \mathrm{m}$ e média 9,3 $\mu \mathrm{m}$.

Dos oito registros, sete espécimes incrustavam raízes de E. azurea e um de E. crassipes. A espécie teve ocorrências já registradas para o Rio Grande do Sul, no rio Jacuí, à jusante da barragem de Itaúba, em Arroio do Tigre; no rio Caí, em Nova Petrópolis; no arroio Biriva e no rio ibicuí-Mirim, em Santa Maria; na lagoa na confluência dos rios Ibicuí-Mirim com Toropí, lagoa junto ao rio Ibicuí, Fazenda Santa Fé, em São Vicente do Sul; rio Jacuí, em General Câmara e em São Jerônimo; no arroio do Conde, rio Jacuí, São Jerônimo/Butiá (De Rosa-Barbosa 1984). 


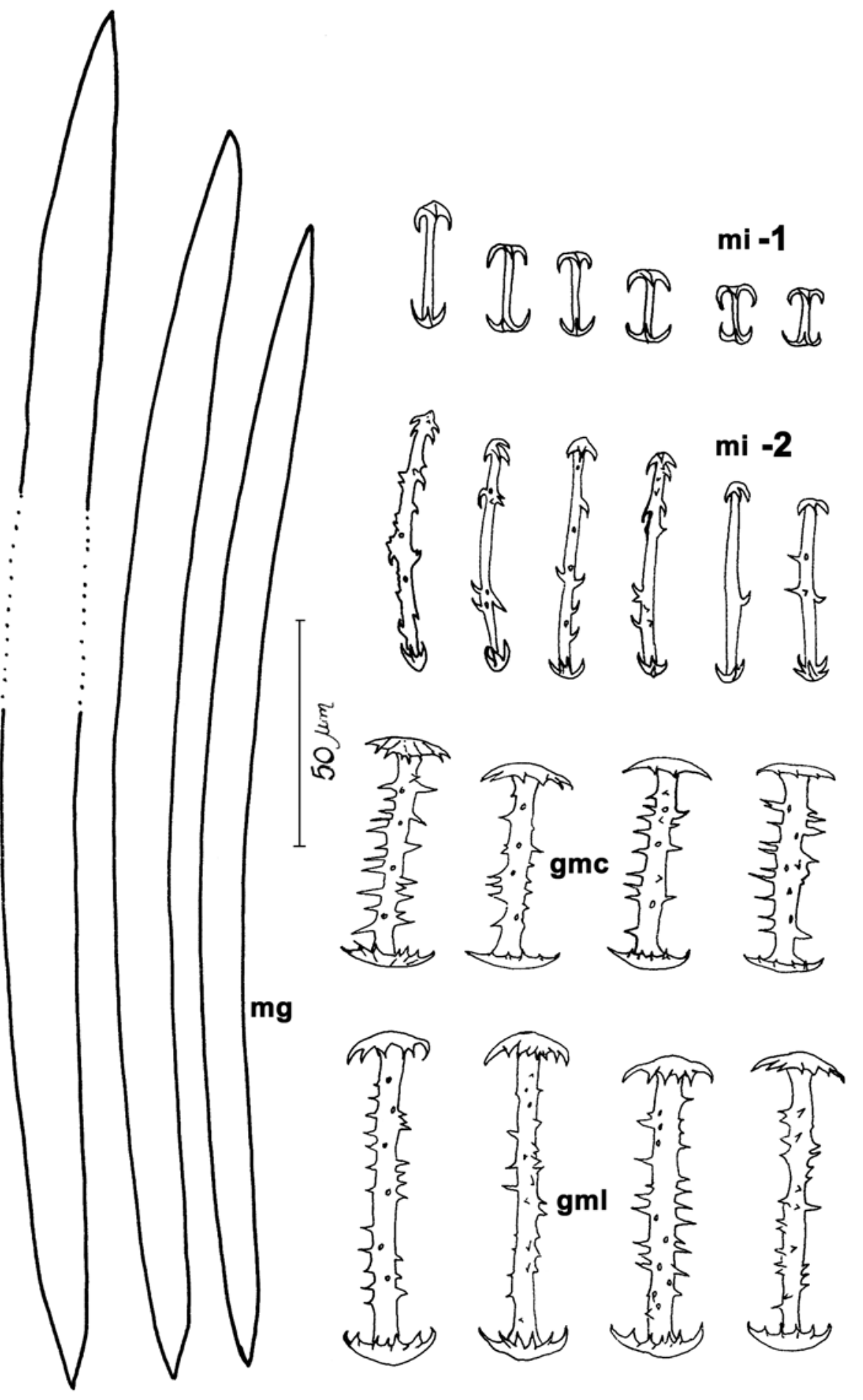

16

Figura 16. Desenhos à câmara lúcida do conjunto espicular de Corvoheteromeyenia australis. Megascleras óxeas (mg), gemoscleras anfidiscos da categoria longa ( $\mathrm{gml}$ ), gemoscleras anfidiscos da categoria curta ( $\mathrm{gmc}$ ), microscleras isoquelas (mi-1), microscleras anfidiscos (mi-2). Escala $50 \mu \mathrm{m}$.

Revista Brasileira de Zoologia 20 (2): 169-182, junho 2003 


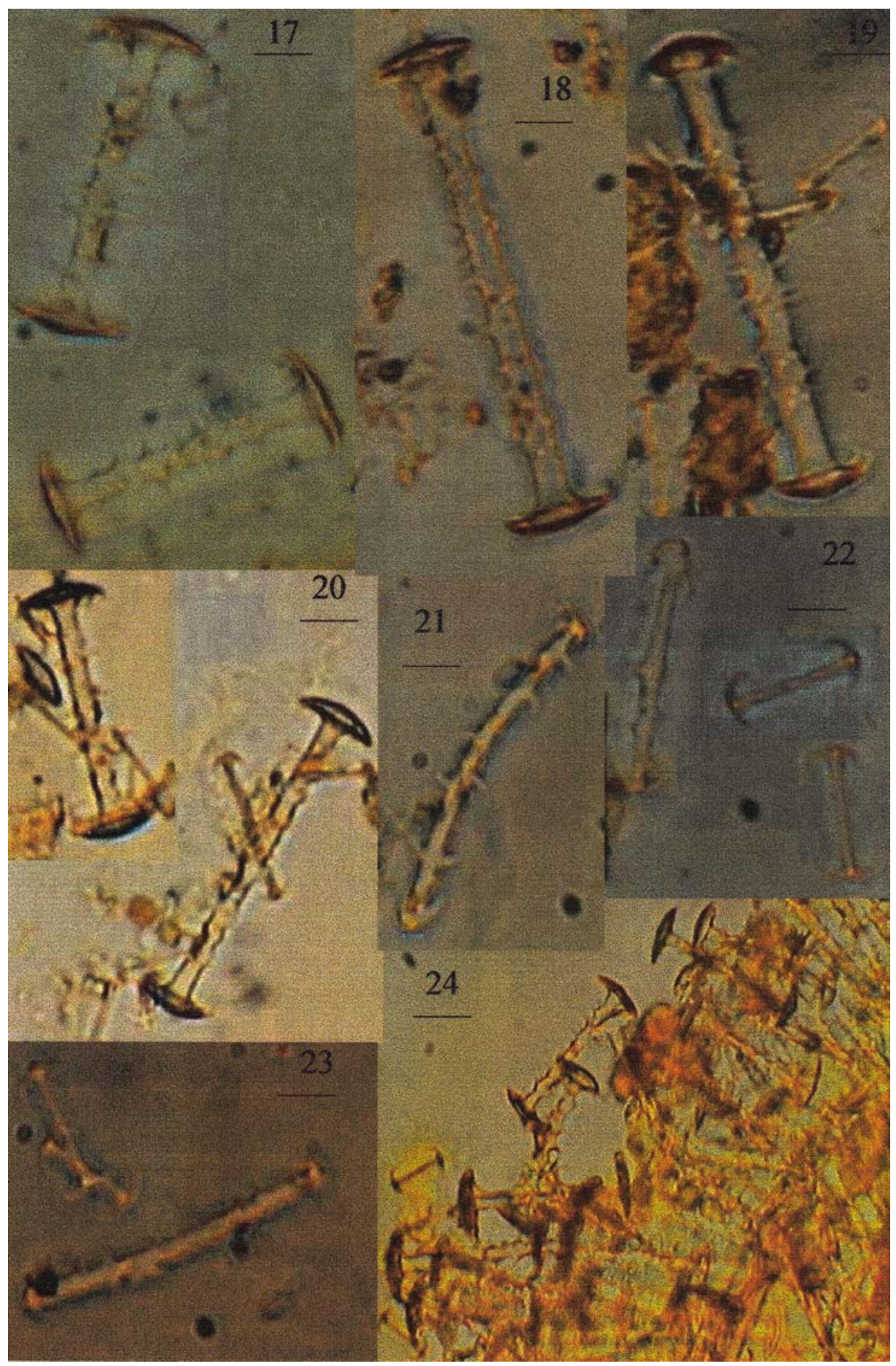

Figuras 17-24. Imagens ao Microscópio Invertido Olympus IX70 do conjunto espicular de Corvoheteromeyenia australis: (17) gemoscleras da categoria curta, escala $9 \mu \mathrm{m}$; (18) gemosclera anfidisco da categoria longa, escala 9,7 $\mu \mathrm{m}$; (19) gemosclera anfidisco da categoria longa, escala 10,3 $\mu \mathrm{m} ;(20)$ gemoscleras das categorias curta e longa, escala $14 \mu \mathrm{m} ;(21)$ microsclera anfidisco, escala 8,2 $\mu \mathrm{m} ;(22)$ microscleras isoquelas e anfidisco, escala $8 \mu \mathrm{m}$; (23) microscleras isoquelas e anfidisco, escala $8 \mu \mathrm{m}$; (24) região parcial de gêmula não dissociada destacando as gemoscleras anfidiscos e algumas microscleras isoquelas, escala 22,4 $\mu \mathrm{m}$. Imagens: M.C.M. Tavares.

Revista Brasileira de Zoologia 20 (2): 169-182, junho 2003 


\section{Variações morfológicas}

Os espécimes coletados são diminutos, no entanto, apresentam-se geralmente numerosos e com uma gama de tamanhos que cobre todas as dimensões entre microespécimes, até as dimensões de $3,0 \mathrm{~cm}$ (Fig. 5). A coloração varia de esbranquiçada a parda (Fig. 4). Tanto fascículos de raízes quanto os caules submersos, particularmente da $E$. azurea, são utilizados como substratos, ocasionando porém formas e estruturas esqueletais distintas, numa mesma espécie, como bem ilustrado pela Radiospongilla amazonensis (Figs 5-6): os espécimes fixos aos caules tomam aspecto de crostas rasas de contorno irregular (Fig. 5) com distribuição mais adensada das fibras do esqueleto e estas perpendiculares ao substrato, as gêmulas encontrandose geralmente junto ao substrato. Já aqueles que se fixaram na região fasciculada das raízes apresentam formatos esféricos, subesféricos ou cilíndricos, com estrutura radial aberta das fibras do esqueleto e superfície nitidamente híspida, com fácil visualização das gêmulas agrupadas entre as fibras, quando estas ocorrem (Fig. 6). As gêmulas são encontradas isoladas ou agrupadas. Uma mesma espécie pode adotar uma ou outra forma e estrutura esqueletal, dependendo de estar incrustando a superfície mais lisa dos caules ou o substrato tridimensional das raízes fasciculadas (Figs 4-6).

\section{Chave para identificação das esponjas do Parque Estadual Delta do Jacuí, Rio Grande do Sul}

1a. As Gemoscleras são anfidiscos ......................................... 2

1b. As Gemoscleras são óxeas ou estrôngilos ......................... 7

2a. Os Anfidiscos tem rótulas umbonadas, c/ bordas recortadas e eixos espinhentos e a esponja tem microscleras ........... 3

2b. Os Anfidiscos tem rótulas em forma de taça, com bordas inteiras ou onduladas, com eixos lisos e a esponja é desprovida de microscleras......

3a. As Microscleras são de dois tipos: anfidiscos com rótulas diminutas, recortadas e eixos delgados espinhentos e isoquelas (Figs 16-24 .................. Corvoheteromeyenia australis

3b. As Microscleras são óxeas espinhentas com extremidades abruptas (Fig. 15) ....................... Heteromeyenia stepanowii

4a. As megascleras são estrôngilos espinhentos (Fig. 13) ........ . Trochospongilla lanzamirandai

4b. As megascleras são óxeas ............................................... 5

5a Megascleras óxeas lisas robustas (Fig. 10)

Trochospongilla paulula

5b Megascleras óxeas espinhentas ...................................... 6

6a. Megascleras óxeas de dois tamanhos, ambas com farta espinhadura essa mais abundante nas extremidades que podem assumir a forma de ponta de arpão (Fig. 12) ....

Trochospongilla minuta

6b Megascleras óxeas de tamanho uniforme com espinhos esparsos ao longo do eixo (Fig. 11)

Trochospongilla variabilis

7a. Gemoscleras óxeas lisas curtas, curvadas ou dobradas em forma de bumerangue (Fig. 9) ............. Oncosclera navicella

7b. Gemoscleras óxeas e estrôngilos espinhentos .................. 8

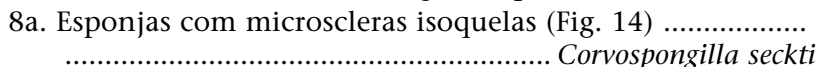

8b. Esponjas sem microscleras .......................................... 9

9a. Gemoscleras estrôngilos com espinhos robustos curvos mais concentrados nas extremidades da espícula, constituindo uma quase rótula (Fig. 8) ......... Radiospongilla amazonensis

9b. Gemoscleras óxeas, raramente estrôngilos com espinhadura conspícua, esparsa e eventualmente mais concentrada nas extremidades das espículas (Fig. 7) .......... Eunapius fragilis

\section{DISCUSSÃO}

Os resultados apresentados permitem caracterizar, dois aspectos importantes da distribuição espacial dos poríferos dulcícolas. O primeiro pertinente à estrutura taxonômica de uma comunidade de esponjas de curso inferior de um rio subtropical sul-americano, contribuindo para o entendimento da zonação longitudinal (Hynes 1970) dessa fauna, aspecto até o presente não abordado na bibliografia de esponjas de áreas continentais. Um delta, mais do que qualquer outra porção ou tipo de curso inferior, caracteriza-se pelo acúmulo dos depósitos sedimentares que tipificam essa secção terminal dos rios. Esses, por sua vez, determinam a ocorrência de linhas de margem propícias à formação dos camalotais ou esteiras de macrófitas flutuantes, constituindo um dos raros substratos disponíveis, nesses locais, para fixação de esponjas, como agora também constatado e registrado pela primeira vez.

O primeiro registro de C. australis, aqui efetuado para o Brasil, consolida a ocorrência do gênero Corvoheteromeyenia no país, além de mantê-lo restrito à Região Neotropical e portanto endêmico dessa Região, tendo em vista que Corvoheteromeyenia heterosclera Ezcurra de Drago, 1974, descrita para o nordeste do Brasil, foi recentemente registrada para os lagos temporários dos Lençóis Maranhenses (VolKmer-Ribeiro et al. 1999), para a Venezuela (Volkmer-Ribeiro \& Pauls 2000) e para Curaçao (Debrot $\&$ vAN SoEst 2001). Confirma-se também a distinção entre as duas espécies que integram o gênero, baseada fundamentalmente nas gemoscleras que, em C. australis, apresentam duas categorias distintas em forma e tamanho (Fig. 16). É característica genérica a incrustação em macrófitas de ambientes lênticos temporários.

O levantamento feito registrou novamente a ocorrência de Eunapius fragilis, Heteromeyenia stepanowii, Trochospongilla paulula, Trochospongilla lanzamirandai e Oncosclera navicella, levou a efeito os primeiros registros de Radiospongilla amazonensis, Trochospongilla minuta e Corvoheteromeyenia australis, não havendo logrado novos registros de Corvospongilla seckti e Trochospongilla variabilis.

A comunidade no presente amostrada, a qual somam-se os registros anteriormente efetuados (VOLKMER-Ribeiro et al. 1975), integra dez espécies que incrustam as partes submersas da vegetação de macrófitas (camalotais) que orla as ilhas desse delta, constituindo portanto uma assembléia que integra tanto o bentos lodoso e móvel (nas raízes de E. azurea) quanto o pleuston (nas raízes de E. crassipes). Oncosclera navicella, E. fragilis e C. seckti constituem exceção a essa regra, pois são espécies que incrustam preferencialmente o bentos rochoso de rios brasileiros (Batista \& Volkmer-Ribeiro 2002). Essas espécies utilizam esporadicamente o substrato de macrófitas, formando espécimes de tamanhos diminutos, ou apenas gêmulas, com raras megascleras circundantes. Esta é a provável razão de sua raridade nesse ambiente levando a ocorrências ocasionais.

Outro fator a ser considerado é a mobilidade dessa vegetação de macrófitas que orla as ilhas, particularmente a constituída pelos aguapés. Esta é renovada periodicamente devido

Revista Brasileira de Zoologia 20 (2): 169-182, junho 2003 
à força e ao volume das águas que chegam ao delta por ocasião de chuvas fortes e constantes nas cabeceiras dos rios formadores do Guaíba. É assim de supor-se que o tempo disponível para essas esponjas se desenvolverem, tanto através de larvas, quanto de dispersão e fixação de gêmulas, é reduzido, ocasionando a ocorrência generalizada de micro-espécimes, muitos ainda sem gêmulas, testemunhos de reprodução sexuada. É obvio que um tal ambiente incutirá uma dinâmica própria e característica às populações dessas esponjas, também obviamente já selecionadas para esse habitat.

Revestem-se de importância ainda, os aspectos levantados quanto à constituição da rede esqueletal dessas esponjas, ditada pelo tipo de substrato, conduzindo a características distintas numa mesma espécie e semelhantes em espécies diferentes, elevando os constituintes espiculares e, particularmente as gemoscleras, à categoria de itens indispensáveis à identificação específica dessa fauna.

\section{AGRADECIMENTOS}

A primeira autora agradece à Pontifícia Universidade Católica do Rio Grande do Sul (PUCRS) e ao Conselho Nacional de Desenvolvimento Científico e Tecnológico (CNPq) pela bolsa de Doutorado concedida; as autoras registram o apoio logístico proporcionado pelo Programa PRO-GUAÍBA/FZB-RS, para a realização dos trabalhos de campo e aquisição de materiais de laboratório, agradecem às colegas do Núcleo de Vegetais Inferiores e Intermediários do MCN/FZB pela orientação na utilização do Microscópio Invertido modelo Olympus IX 70 com câmara digital associada ao sistema computacional ImagePro Plus versão 4.1.0.0 e aos consultores Cléa Beatriz Lerner e ao anônimo pelas sugestões e correções indicadas.

\section{REFERÊNCIAS BIBLIOGRÁFICAS}

Batista, T.C. A. \& C. Volkmer-Ribeiro. 2002. Comunidades de esponjas do curso superior dos rios Paraná (Goiás) e Paraguai (Mato-Grosso), Brasil, com redescrição de Oncosclera schubarti Bonetto \& Ezcurra de Drago. Revista Brasileira de Zoologia, Curitiba, 19 (1): 123-136.

BonetTo, A.A. \& I. Ezcurra. 1964. Nuevas esponjas de agua dulce de la República Argentina. Physis, Buenos Aires, 24 (68): 329-336.

Bonetto, A.A. \& I. Ezcurra de Drago. 1966. Nuevos aportes al conocimiento de las esponjas argentinas. Physis, Buenos Aires, 26 (71): 129-140.

. 1967. Esponjas del noreste argentino. Acta Zoologica Lilloana, Tucumán, 23 (1): 331-347.

. 1969. Notas sistemáticas sobre el género Uruguaya Carter (Porifera, Spongillidae). Physis, Buenos Aires, 28 (77): 351-377.

— 1970. Esponjas de los afluentes del Alto Paraná en la provincia de Misiones. Acta Zoologica Lilloana, Tucumán, 27: 37-61.

- 1973. Las esponjas del género Trochospongilla Vejdovsky en aguas argentinas. Physis, Buenos Aires, 32 (84):13-8.

Bowerbank, J.S. 1863. A monograph of the Spongillidade. Proceedings of the Zoological Society of London 1863: 440-472.

CARTER, H.J. 1881. History and classification of the know species of Spongilla. Annals and Magazine of Natural History, London, 5 (7): 77-107.

Debrot, A.O. \& R.W.M. van Soest. 2001. First records of the freswhater sponges Corvoheteromeyenia heterosclera and Spongilla alba (Porifera: Spongillidae) from Curaçao, with species descriptions and data from transplantation experiments. Caribbean Journal of Science, Mayagüez, 37 (1-2): 88-94.

Dүвошsку, W. 1884. Notiz über die aus Süd-Russland stammenden Spongillen. Sitzungsberichte der Naturforsscher Gesselschaft zu Dorpat 6: 507-515.

Ezcurra de Drago, I. 1979. Un nuevo género sudamericano de esponjas: Corvoheteromeyenia gen. nov. (Porifera Spongiliidae). Neotropica 25 (74): 109-118.

FundaÇÃo ZoObotânICA do Rio Grande do Sul. 1976. Preceituação Ecológica para Preservação dos Recursos Naturais na Região da Grande Porto Alegre. Fundação Zoobotânica do Rio Grande do Sul, Livraria Sulina, 153p.

HyNes, H.B.N. 1970. The ecology of running waters, University Press, $555 \mathrm{p}$.

LEYDY, J. 1851. Spongilla fragilis. Proceedings of the Academy of Natural Sciences of Philadelphia 5: 278.

Oliveira, M.L.A.A. \& M.L. Porto. 1999. Ecologia de paisagem do Parque Estadual Delta do Jacuí, Rio Grande do Sul, Brasil: mapa da cobertura do solo e da vegetação, a partir de imagem do LANDSAT TM5. Iheringia, Série Botânica, Porto Alegre, 52: 145-162.

Penney, J.T. \& A.A. Racek. 1968. Compreensive revision of a woldwide collection of freshwater sponges (Porifera: Spongillidae). Bulletin of the United States Natural Museum, Washington, D.C., 272: 1-184.

Porto Alegre. 1979. Secretaria do Planejamento Municipal. Grupo de Planejamento do Parque Estadual Delta do Jacuí. Parque Estadual Delta do Jacuí: plano básico. Porto Alegre, Série Planejamento Municipal 3, Parque Estadual Delta do Jacuí1, Plandel, 88p.

. 2001. Departamento Municipal de Água de Esgotos (DMAE), Monitoramento das águas do Delta e foz dos rios formadores do Guaíba. Ecos Pesquisa 5, Porto Alegre, p. 163.

PotTs, E. 1882. Three more freshwater sponges. Proceedings of the Academy of Natural Sciences of Philadelphia 34: 12-14.

. 1887. Contributions towards a synopsis of the american forms of freshwater sponges with descriptions of those named by other authors and form all parts of the world. Proceedings of the Academy of Natural Sciences of Philadelphia 39: 158-279.

De Rosa-Barbosa, R. DE. 1984. Reavaliação da fauna espongológica continental do Estado do Rio Grande do Sul, Brasil, frente a novas coletas. Iheringia, Serie Zoologia Porto Alegre, 64: 127-148.

. 1988. Corvospongilla volkmeri sp.n. e registro de Corvospongilla seckti Bonetto \& Ezcurra de Drago, 1966 no Brasil (Porifera, Spongillidae). Iheringia, Serie Zoologia, Porto Alegre, 67: 109-122.

Tavares, M.C.M. \& C. Volkmer-Ribeiro. 1997. Redescrição das esponjas de água doce Oncosclera navicella (Carter, 1881) (Potamolepidae) e Spongilla spoliata Volkmer-Ribeiro \& Maciel (Spongillidae). Biociências, Porto Alegre, 5 (1): 97-111. 
VolKMER-Ribeiro, C. 1970. Oncosclera - a new genus of freshwater sponges (Porifera - Spongillidae) with redescription of two species. Amazoniana, Kiel, 2 (4): 435-442.

. 1973. Redescription and ecomorphic variations of the freshwater sponge Trochospongilla ninuta (Potts, 1977). Proceedings of the Academy of Natural Sciences of Philadelphia 125 (8): 137-144. . 1985. Manual de técnicas para preparação de coleções zoológicas. 3. Esponjas de água doce. São Paulo, Sociedade Brasileira de Zoologia, p. 1-6.

Volkmer-Ribeiro, C.; B. Mothes-de-Moraes; R. De Rosa-Barbosa; M.C.D. Mansur \& I. Veitenheimer-Mendes. 1984. Um Estudo do Bentos em raízes de Eichhornia azurea (S.W.) Kunh do curso inferior de um rio subtropical sul-americano. Revista Brasileira de Biologia, Rio de Janeiro, 2 (44): 125-132.

Volkmer-Ribeiro, C.; K.M. Grosser; R. de Rosa-Barbosa \& S.M. PAuls. 1975. Primeiro relato da ocorrência de Espongilídeos (Porifera) na bacia do Guaíba, Estado do Rio Grande do Sul. Iheringia, Série Zoologia, Porto Alegre, 46: 33-49.

Volkmer-Ribeiro, C. \& K.M. Grosser. 1981. Gut contents of Leporinus obtusidens "sensu" von iheringia (Pisces, Characoidei) used in a survey for freshwater sponges. Revista Brasileira de Biologia, Rio de Janeiro, 41 (1): 175-183.

Volkmer-Ribeiro, C.; M.M.F. Correia; S.L.A. Brenha \& M.A. MenDONÇA. 1999. Freshwater sponges from a neotropical sand dune área. Memoirs of the Queensland Museum 44: 643-649.

Volkmer-Ribeiro, C. \& R. De Rosa-Barbosa. 1972. On Acalle recurvata (Bowerbank, 1863) and an associated fauna of other freshwater sponges. Revista Brasileira de Biologia, Rio de Janeiro, 32 (3): 303-317.

. 1985. Redescription of the freshwater sponges Trochospongilla amazonica (Weltner, 1895) with an account of the South American species of Trochospongilla (Porifera, Spongillidae). Iheringia, Série Zoologia, Porto Alegre, 65: 77-93.

Volkmer-Ribeiro,C.; R. de Rosa-Barbosa \& M.C.D. Mansur. 1981. Fauna espongológica e malacológica bêntica da Lagoa Negra, Parque Estadual de Itapuã, Rio Grande do Sul. Iheringia, Série Zoologia, Porto Alegre, 59:13-24.

Volkmer-Ribeiro, C. \& S.B. Maciel. 1983. New freshwater sponges from amazonian waters. Amazoniana, Kiel, 8 (2): 255-264.

Volkmer-Ribeiro, C. \& S.M. Pauls. 2000. Esponjas de agua dulce (Porifera, Demospongiae) de Venezuela. Acta Biológica Venezuelana, Caracas, 20 (1): 1-28.

Recebido em 28.X.2002; aceito em 20.III.2003.

Revista Brasileira de Zoologia 20 (2): 169-182, junho 2003 